\title{
Migration history and stock structure of two putatively diadromous teleost fishes, as determined by genetic and otolith chemistry analyses
}

\author{
Daniel J. Schmidtt ${ }^{1,7}$, David A. Crook ${ }^{2,3,8}$, Jed I. Macdonald ${ }^{2,4,9}$, Joel A. Huey ${ }^{1,10}$, Brenton P. \\ Zampatti $^{5,11}$, Stuart Chilcott ${ }^{6,12}$, Tarmo A. Raadik ${ }^{2,13}$, and Jane M. Hughes ${ }^{1,14}$ \\ ${ }^{1}$ Australian Rivers Institute, Griffith University, Nathan, Queensland 4111, Australia \\ ${ }^{2}$ Arthur Rylah Institute for Environmental Research, Department of Sustainability and Environment, Heidelberg, Victoria 3084, \\ Australia \\ ${ }^{3}$ Research Institute for Environment and Livelihoods, Charles Darwin University, Darwin, Northern Territory 0909, Australia \\ ${ }^{4}$ Institute of Biology, University of Iceland, Sturlugata 7, 101 Reykjavík, Iceland \\ ${ }^{5}$ SARDI Aquatic Sciences, Henley Beach, South Australia 5022, Australia \\ ${ }^{6}$ Department of Primary Industries, Parks, Water and Environment, Hobart, Tasmania 7008, Australia
}

\begin{abstract}
Migratory life cycles and population structure of 2 putatively diadromous Australian fishes were examined using otolith chemistry $\left({ }^{87} \mathrm{Sr} /{ }^{86} \mathrm{Sr}\right.$ ) and genetics (microsatellites and mitochondrial deoxyribonucleic acid [mtDNA]). Australian whitebait (Lovettia sealii) is widely considered to be one of only a few anadromous fish species in the southern hemisphere. The congolli or tupong (Pseudaphritis urvillii) is reported to undertake an unusual form of sexually segregated catadromous migration, where females switch habitats between marine and freshwater, while males remain in marine or estuarine environments. Sr-isotope profiles of L. sealii showed this species does not move into fully freshwater habitats during its life cycle, suggesting it should be considered semianadromous or estuarine-dependent, rather than truly anadromous. This life-history strategy is unique among the Galaxiidae. Lovettia sealii is regionally divided into at least 3 well differentiated genetic stocks: northern and southern Tasmanian coasts and mainland Australia. Sr-isotope profiles of P. urvillii showed that females are catadromous, with the early life history spent in the marine environment and a single migratory transition from marine to freshwater occurring at an early point in the life history. Lack of bidirectional adult migration between freshwater and the sea suggests that female $P$. urvillii are semelparous, returning to the marine habitat to mate with resident males after an extended period of freshwater residence. Pseudaphritis exhibit weak genetic structure across their mainland range. An isolation-by-distance relationship describes the genetic structure of this species, a pattern it shares with several other nearshore-restricted catadromous fishes.
\end{abstract}

Key words: Microsatellites, mitochondrial DNA, otolith chemistry, Sr isotopes, migration, standardized FST, Pseudaphritidae, Galaxiidae

Diadromy is a habitat-switching life-history strategy involving migration between freshwater and marine waters for completion of the life cycle (Myers 1949). Diadromous migration provides opportunity for connectivity among subpopulations via the ocean, but the magnitude and spatial configuration of this connectivity is variable and influenced by many factors. Some of these include the form of diadromy exhibited by a species (e.g., anadromy, catadromy, amphidromy; McDowall 1988), the existence of philopatric behavior (e.g., natal homing; Vaha et al. 2007), environmen- tal and ecological variables (e.g., coastal distance and temperature regime; Dionne et al. 2008), and historical events (e.g., glaciation and sea-level fluctuation may subdivide a species into demographically independent stocks; King et al. 2001). The widespread distribution of many diadromous taxa is attributable to oceanic connectivity (McDowall 2008). More-limited distributions of some species may be explained, at least in part, by shorter larval durations in the ocean and distance travelled from shore (Sorensen and Hobson 2005, Lord et al. 2012).

E-mail addresses: ${ }^{7}$ d.schmidt@griffith.edu.au; ${ }^{8}$ david.crook@cdu.edu.au; ${ }^{9}$ jedimacdonald@gmail.com; ${ }^{10}$ j.huey@griffith.edu.au
${ }^{11}$ brenton.zampatti@sa.gov.au; ${ }^{12}$ stuart.chilcott@dpipwe.tas.gov.au; ${ }^{13}$ tarmo.raadik@dse.vic.gov.au; ${ }^{14}$ jane.hughes@griffith.edu.au 
The Australian native fish fauna includes $\sim 33$ diadromous species, most of which are poorly understood in terms of migratory movements and population structure (McDowall 1988, Miles 2007). Catadromy and amphidromy are the most common forms of diadromy in Australian fishes, whereas the dominant form in the northern hemisphere (anadromy; McDowall 2008) is recognized in only 4 Australian species (Lovettia sealii, Retropinna tasmanica, Geotria australis, and Mordacia mordax; McDowall 1988, Miles 2007). Catadromy involves migration of adults from freshwater reaches to marine habitat for the purpose of reproduction. Juveniles then return to freshwater for growth and development (McDowall 1988). Anadromy is the reverse of catadromy, so that adults reside in the marine environment and migrate to freshwater for breeding (McDowall 1988). In amphidromy, the switch between habitats is not for the purpose of reproduction. Instead, adults reside and reproduce in freshwater and larvae migrate passively to the marine habitat for a period of early growth before returning to freshwater as juveniles (McDowall 1988).

The current deficient state of knowledge of Australian diadromous fishes, at least in part, reflects the difficulty of monitoring movements of small larval and juvenile fish that can travel potentially great distances between different habitats. Otolith chemistry is an indirect method well suited to overcome this problem and can be used to estimate the movement of an individual fish across different chemical environments throughout its lifetime (Gillanders 2005, Walther and Limburg 2012). Otoliths (earstones) grow continuously and provide a permanent record of environmental conditions experienced by a fish throughout its life that can be recovered by measuring particular elemental (e.g., $\mathrm{Sr} / \mathrm{Ca}, \mathrm{Ba} / \mathrm{Ca})$ or isotopic $\left({ }^{87} \mathrm{Sr} /{ }^{86} \mathrm{Sr}\right)$ ratios that differ among habitats (Gillanders 2005, Walther and Limburg 2012). Therefore, otolith chemistry is useful for discerning whether diadromy occurs in a species or population, for determining which form of diadromy occurs, and for assessing whether variation exists among individuals or populations in the incidence of diadromous migration (Milton and Chenery 2005, Crook et al. 2008, Chapman et al. 2012).

Otolith chemistry can reveal within-lifetime migration patterns, but estimates of population connectivity require methods that integrate movements of successful dispersers over many generations. Genetic data is complementary to otolith chemistry in this regard. Inferences from genetic analyses may be applied over large spatial scales to infer stock structure and evolutionary history (Waples et al. 2008, Griffiths et al. 2010, Feutry et al. 2013) or over small scales to infer demographic parameters, such as population size and migration rate (Lowe and Allendorf 2010). Genetic studies of anadromous fishes indicate that most species exhibit an isolation-by-distance (IBD) pattern of genetic connectivity at scales of up to several thousand kilometers of coastline (Bradbury and Bentzen 2007). IBD is a positive association between genetic and geographic distance in which subpopulations are linked by dispersal in a steppingstone fashion. This pattern probably is a product of limited dispersal resulting from natal homing, which is almost ubiquitous among anadromous fishes (McDowall 2001). Lampreys are one of the few exceptions to natal homing in this group, and they exhibit low levels of genetic structure and very weak IBD relative to other anadromous taxa (Waldman et al. 2008, Spice et al. 2012).

Catadromous fish encompass several patterns of genetic connectivity including panmixia, the absence of genetic structure because of random gene flow among demes. Such a pattern exists in anguillid eels, where all spawning in a species occurs within a single region of the ocean and the return juvenile migration may involve distances of $>5000 \mathrm{~km}$ (Als et al. 2011). Catadromous fishes that breed in estuaries or inshore waters often show low levels of structuring with an IBD pattern of population connectivity (Keenan 1994, Shaddick et al. 2011). This pattern probably indicates that juvenile migration back into rivers is not random but is spatially restricted to some extent, either by limited pelagic larval duration or retention of juveniles within the natal estuary (see also Feutry et al. 2013). Amphidromous taxa show the weakest level of population structure among diadromous species. Most are either panmictic or have very low levels of population structure, regardless of whether they occur in the tropics or have temperate continental distributions (Crandall et al. 2010, Schmidt et al. 2011, Cook et al. 2012). Genetic structuring detected at large spatial scales for some widespread amphidromous species is attributed to biogeographic history and does not reflect contemporary patterns of migratory behavior in these taxa (e.g., Waters et al. 2000, Lord et al. 2012).

Coupling otolith chemistry with genetic analysis is a promising approach for understanding the ecological, evolutionary, and conservation implications of diadromous migration. These methods were applied to 2 diadromous fish species endemic to temperate southeastern Australia. Our goals were to assess: 1) whether transects of Sr isotope $\left({ }^{87} \mathrm{Sr} /{ }^{86} \mathrm{Sr}\right)$ ratios through otoliths of Lovettia sealii (Johnston) and Pseudaphritis urvillii (Valenciennes) (Pseudaphritidae) are consistent with habitat switching between freshwater and marine environments by these species, 2) whether migratory behavior varies among or within populations, 3) whether multiple stocks can be discriminated within each species using genetic data, and 4) to define a spatial pattern of genetic connectivity among subpopulations.

\section{METHODS}

\section{Study species}

The Australian whitebait L. sealii is a small, slenderbodied monotypic member of the Galaxiidae, formerly only known from coastal rivers of Tasmania until recently discovered across Bass Strait at a single locality on mainland 
Australia (Allen et al. 2002, Raadik 2008a). Lovettia sealii is classified as anadromous (McDowall 1988, Allen et al. 2002, Gillanders 2005, Miles 2007), but this classification is based on a single study (Blackburn 1950). Current understanding is that sexually maturing adults migrate upstream from the sea during the late austral winter to early summer, spawning occurs in upper estuarine reaches after which most adults deteriorate in condition and die, and larvae are then transported back toward the ocean (Blackburn 1950). Whether all larvae enter the open ocean and whether growth and development occur in the ocean or closer to shore have not been verified. However, an unpublished study suggested that some larvae remain within the estuary in Tasmania (Fulton and Pavuk 1988), and juveniles ( $<45 \mathrm{~mm}$ total length) have been recorded in April from within a coastal inlet on mainland Australia by one of us (TR, personal observation). Blackburn (1950) proposed that $L$. sealii consists of 2 independent stocks in northern and southern Tasmania based on differences in pigmentation, growth, timing of spawning runs, and distribution. Support for multiple stocks was provided by unpublished allozyme studies that resolved a well differentiated northern and southern region (Pavuk 1994). Fulton and Pavuk (1988) and Pavuk (1994) also proposed several other genetic stocks. However, these results may have been disproportionately influenced by a single locus (PEP A), and it is possible that this estimate of genetic structure was biased by selection. A significant commercial whitebait fishery existed in Tasmania from 1941 to 1974, and L. sealii made up $\sim 95 \%$ of the catch (Blackburn 1950, Fulton 2000). Catches crashed by the 1950 s, leading to closure of the fishery, which reopened in 1990 for recreational purposes under limited seasonal operation (Fulton 2000). Many diadromous fishes have suffered similar precipitous declines over the last century because of overfishing, barriers to migration, and pollution (Limburg and Waldman 2009). A better understanding of population structure and migratory behavior of $L$. sealii is warranted for more-informed management and conservation of the species, particularly considering its recently discovered transBassian distribution.

Pseudaphritis urvillii (commonly known as congolli or tupong) is a nonAntarctic member of the icefish suborder Notothenioidei (Near et al. 2004) and is endemic to and common in coastal rivers of southeastern Australia, including Tasmania (Allen et al. 2002, Raadik 2008b). Pseudaphritis urvillii is currently classified as catadromous (McDowall 1988, Gillanders 2005, Miles 2007). An unusual sexually dimorphic residence behavior appears to exist where adult females reside in freshwater habitats and undertake downstream migration to the sea where spawning occurs (Crook et al. 2010). Males reside either in estuaries or the sea (Hortle 1979, BZ, personal observation). The spatial scale of movements made during the juvenile phase is unknown, and no information exists on population structure. Population declines may have occurred at range margins of the mainland distribution in South Australia and New South Wales (Miles 2007, Hammer et al. 2009). Barriers that inhibit migratory movements required to complete the life cycle are implicated in these declines. These barriers may include infrastructure, such as dams and weirs, or decreases in water level caused by drought and water abstraction (Rolls 2011, Wedderburn et al. 2012). For example, dramatic population declines of juvenile $P$. urvillii migrating upstream were observed during a recent drought and were attributed to failed recruitment caused by limited access of reproductively mature females to estuarine/marine spawning habitats (Zampatti et al. 2010).

\section{Field sampling}

Samples of $L$. sealii were collected using hand-held dip nets from the upper estuarine reaches of 5 coastal rivers, including 3 from northern Tasmania and 2 from southern Tasmania, and by trawl from 1 mainland site, Anderson Inlet (= Tarwin River), Victoria (used only for genetic analysis) (Fig. 1A, Table 1). The sample from Black River consisted of a single individual, which was used for otolith analysis but not for genetics. Female P. urvillii were sampled by electrofishing from the freshwater reaches of 8 coastal rivers upstream of tidal influence, including 7 mainland sites and 1 from northern Tasmania (Fig. 1B, Table 1). The sample from Hopkins River was used for otolith analysis but not for genetics. Where possible, 30 individuals of each species were sampled per site. All procedures were carried out according to Australian Ethics Commission protocol number ENV/ 01/09/AEC.

\section{Water collection and analysis}

Water samples were collected from the lower freshwater reaches of each study river for analysis of ${ }^{87} \mathrm{Sr} /{ }^{86} \mathrm{Sr}$. At least 1 sample was collected for each location included in the otolith analysis and multiple (2-3) samples were analyzed from several localities to check for temporal variation in ${ }^{87} \mathrm{Sr} /{ }^{86} \mathrm{Sr}$ (Victoria: summer 2008/2009, winter 2009; Tasmania: autumn 2009, spring 2009). Based on repeat sampling of sites in our study and from other Tasmanian rivers (DC, unpublished data), temporal variation in ${ }^{87} \mathrm{Sr} /{ }^{86} \mathrm{Sr}$ was minor relative to among-site variation (Table 1 ), so a single water sample from each site was regarded as sufficient for the purpose of our study. Samples were collected in 125-mL acid-washed polyethylene bottles, refrigerated at $4^{\circ} \mathrm{C}$, and transferred to the School of Earth Sciences, University of Melbourne. Twenty-milliliter aliquots of each water sample were filtered through a $0.2-\mu \mathrm{m}$ Acrodisc syringemounted filter (Pall Corporation, Ann Arbor, Michigan) into a clean polystyrene beaker and dried overnight in a high efficiency particulate air (HEPA)-filtered fume cup- 


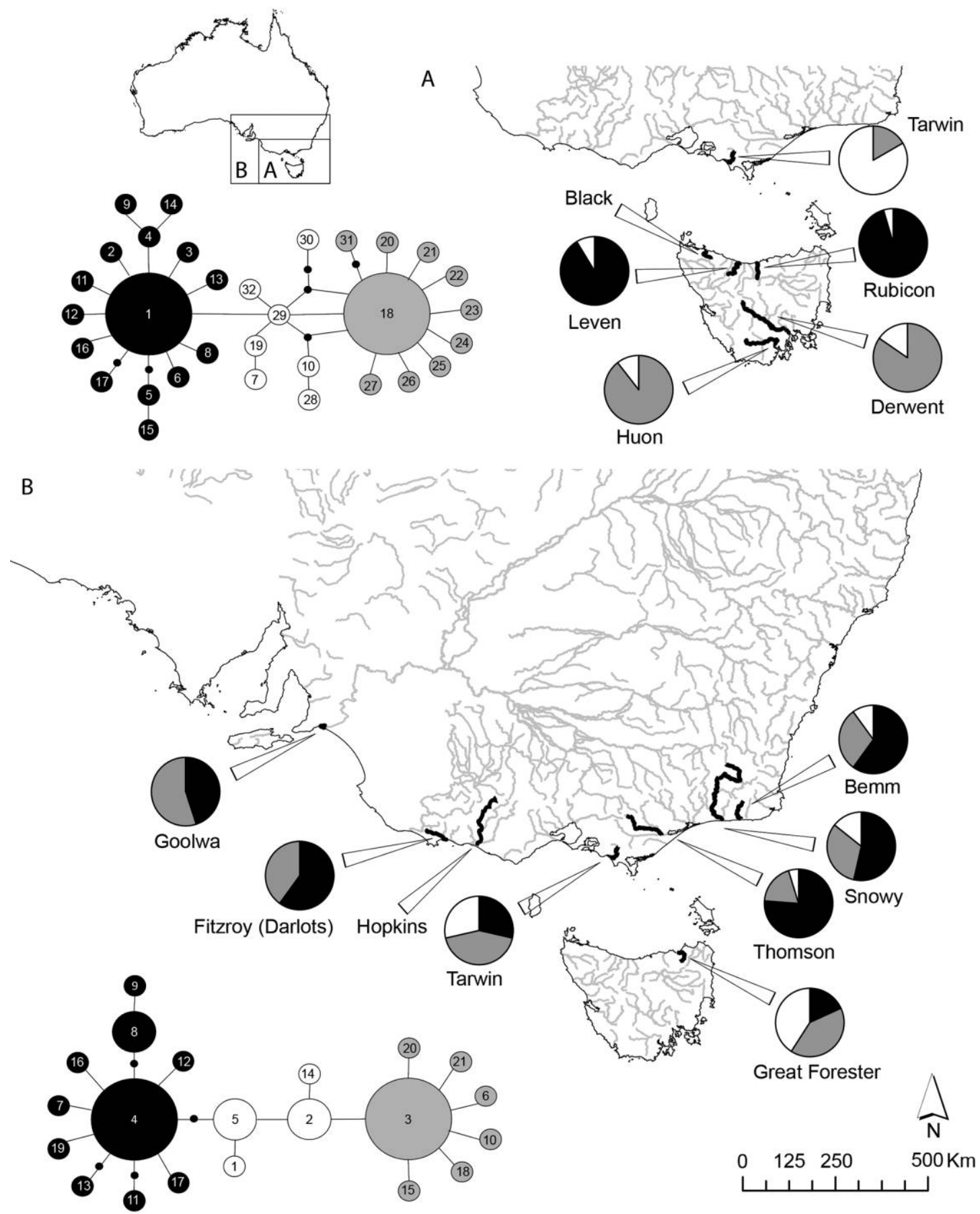

Figure 1. Sampling locations (black bolded waterways) and mitochondrial deoxyribonucleic acid (mtDNA) data summary for Lovettia sealii (A) and Pseudaphritis urvillii (B). Frequency pies depict relative frequency of mtDNA haplotypes in 3 arbitrary groups shaded black, grey, and white in network diagrams. Rivers without frequency pies were included in the otolith chemistry analysis but not genetics. Haplotype codes in mtDNA network diagrams correspond with data presented in Tables S1, S2.

board. Previous analyses have shown that filtering after transfer to the laboratory, rather than after sample collection in the field, has no influence on measurement of ${ }^{87} \mathrm{Sr} /{ }^{86} \mathrm{Sr}$ (e.g., Palmer and Edmond 1989).

Sr was extracted with a single pass over $0.15-\mathrm{mL}(4 \times 12$ $\mathrm{mm}$ ) beds of EICHROM ${ }^{\mathrm{TM}}$ Sr resin $(50-100 \mu \mathrm{m}$; Eichrom
Technologies, Lisle, Illinois). Following Pin et al. (1994), matrix elements were washed off the resin with $2 \mathrm{M}$ and $7 \mathrm{M} \mathrm{HNO}_{3}$, followed by elution of clean $\mathrm{Sr}$ in $0.05 \mathrm{M}$ $\mathrm{HNO}_{3}$. The total blank, including syringe-filtering, was $\leq 0.1 \mathrm{ng}$, implying sample to blank ratios of $\geq 4000$, so no blank corrections were deemed necessary. Sr-isotope anal- 


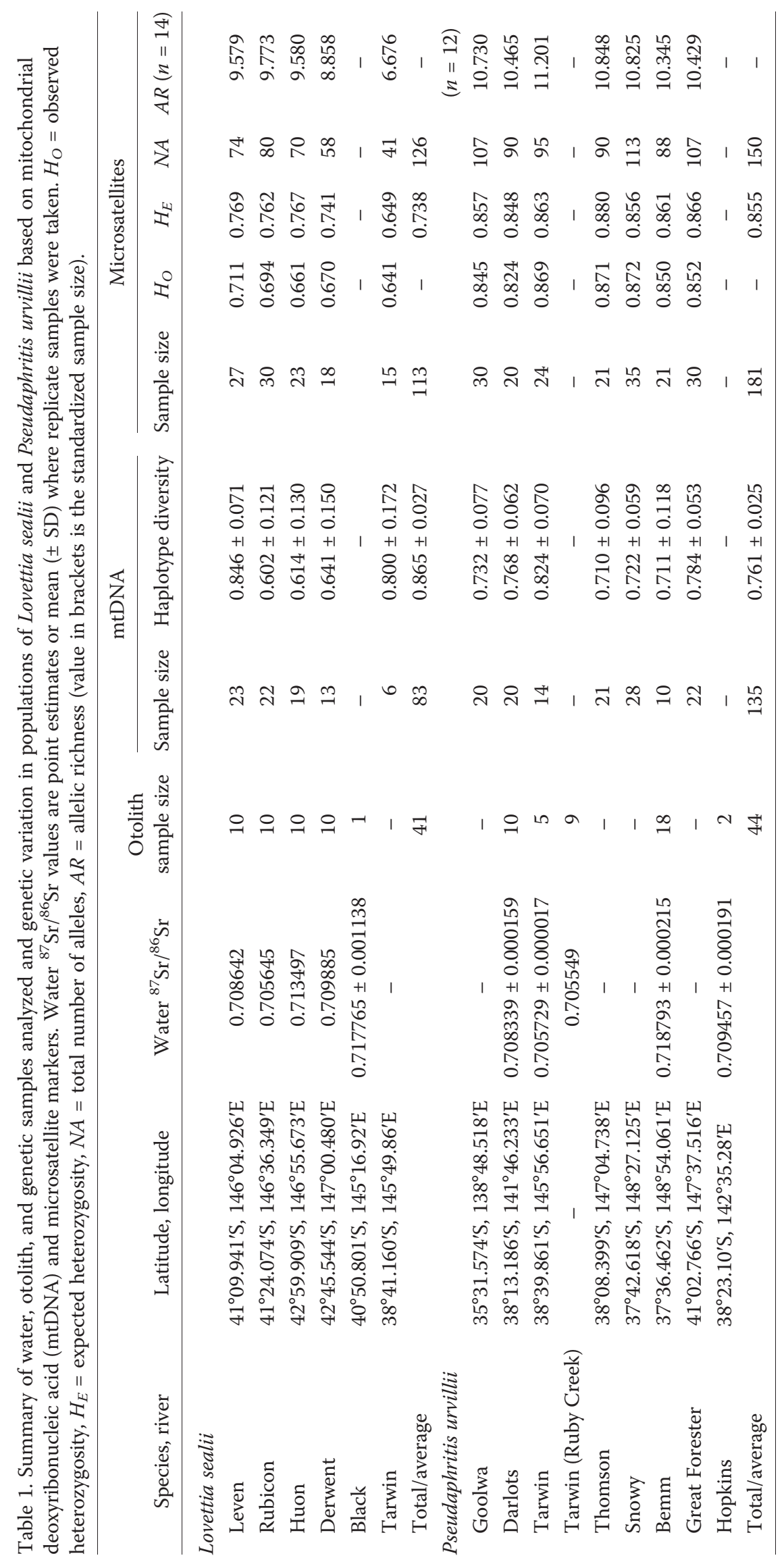


yses were carried out on a $\mathrm{Nu}$ Plasma multicollector inductively coupled plasma mass spectrometer ( $\mathrm{Nu}$ Instruments, Wrexham, UK) interfaced with an Aridus ${ }^{\mathrm{TM}}$ desolvating nebulizer (CETAC, Omaha, Nebraska), operated at an uptake rate of $\sim 40 \mu \mathrm{L} / \mathrm{min}$ (Maas et al. 2005). Mass bias was corrected by normalizing to ${ }^{88} \mathrm{Sr} /{ }^{86} \mathrm{Sr}=8.37521$, and results were reported relative to a value of 0.710230 for the SRM987 Sr isotope standard. Internal precisions $( \pm 2 \mathrm{SE})$ based on at least thirty 10-s integrations averaged \pm 0.00002 and average reproducibility ( \pm 2 SD) was \pm 0.00004 .

\section{Otolith dissection and preparation}

Sagittal otoliths were dissected and mounted individually, proximal surface downward, on an acid-washed glass slide in thermoplastic glue (Crystalbond ${ }^{\mathrm{TM}}$; Aremco Products Inc., New York) and polished down to the primordium with a graded series of wetted lapping films $(9,5,3 \mu \mathrm{m})$ and alumina slurry $(0.5 \mu \mathrm{m})$. The slide was then reheated, and the polished otolith was transferred to a master slide, on which otoliths from all collection sites were combined and arranged randomly to remove any systematic bias during analysis. The samples were rinsed several times in Milli-Q water (Millipore Corporation, Billerica, Massachusetts) and air dried overnight in a class-100 laminar flow cabinet at room temperature.

\section{Sr isotope analysis}

Laser ablation-inductively coupled plasma mass spectrometry (LA-ICPMS) was used to measure ${ }^{87} \mathrm{Sr} /{ }^{86} \mathrm{Sr}$ in the otoliths with a Nu Plasma multi-collector LA-ICPMS (Nu Instruments) coupled to a HelEx laser ablation system (Laurin Technic, Canberra, Australia, and the Australian National University) built around a 193-nm Compex 110 excimer laser (Lambda Physik, Gottingen, Germany). Otolith mounts were placed in the sample cell and the primordium of each otolith was found visually with a video imaging system (GeoStar version 6.14; Resonetics, Nashua, New Hampshire). The intended ablation transect on each sample was plotted digitally and each otolith was then ablated along this transect from the primordium to the dorsal margin at the widest radius using a $6 \times 100-\mu \mathrm{m}$ rectangular laser slit. The laser was operated at $90 \mathrm{~mJ}$, pulsed at $10 \mathrm{~Hz}$, and scanned at $3 \mu \mathrm{m} / \mathrm{s}$ across the sample. Ablation was done under an atmosphere of pure He to minimize redeposition of material, and the sample was then rapidly entrained into the Ar carrier gas flow. A preablation step using reduced energy $(50 \mathrm{~mJ})$ was conducted along each transect to remove any surface contaminants, and a 20 - to 60 -s background was measured before acquiring data for each sample. Potential $\mathrm{Kr}$ interferences were corrected by subtracting baselines on peak before each analysis, and corrections for ${ }^{87} \mathrm{Rb}$ interferences were made following the method of Woodhead et al. (2005), assuming a natural ${ }^{87} \mathrm{Rb} /{ }^{85} \mathrm{Rb}$ ratio of 0.3865 . Mass bias was then corrected by reference to an ${ }^{86} \mathrm{Sr} /{ }^{88} \mathrm{Sr}$ ratio of
0.1194. Iolite (version 2.13; Paton et al. 2011) was used to process data offline, and possible interferences from $\mathrm{Ca}$ argide/dimer species were corrected during this step. A modern marine carbonate (MMC) standard composed of mollusk shells was analyzed after every 10 otolith samples. Mean ${ }^{87} \mathrm{Sr} /{ }^{86} \mathrm{Sr}$ from 22 analyses of the MMC standard was $0.70917 \pm 0.00011$ ( \pm 2 SD), identical within error to the accepted modern seawater value of 0.70916 (McArthur and Howarth 2004).

\section{Genetic data collection}

Genomic deoxyribonucleic acid (DNA) was extracted from fin tissue using a standard phenol-chloroform extraction (Sambrook et al. 1989). For the L. sealii samples, a fragment of mitochondrial DNA (mtDNA) was amplified by polymerase chain reaction (PCR) using primers HYPSL510 and PH15938 for the 3' end of cytochrome $b$ (cyt $b$ ) (Thacker et al. 2007). These primers yielded poor amplification success, so a fragment spanning adenosine triphosphate (ATP) synthase subunit 8 and ATP synthase subunit 6 genes was amplified and sequenced using primers and protocols described by Woods et al. (2010). For the $P$. urvillii samples, mtDNA data were generated using cyt $b$ primers as described above. Sequencing was done on a 3130xl Genetic Analyser (Applied Biosystems, Foster City, California) at Griffith University DNA sequencing facility. Sequences were edited and aligned using Sequencher (version 4.1.2; (GeneCodes Corp., Ann Arbor, Michigan) and deposited in GenBank under accession numbers KC992794-KC992815 (Tables S1, S2).

Microsatellite markers developed for $L$. sealii and P. urvillii were amplified and genotyped using primers developed by Schmidt et al. (2013). Six loci were used for L. sealii (lsea009, lsea012, lsea013, lsea019, lsea021, lsea023), and 7 loci were used for P. urvillii (purv002, purv004, purv005, purv008, purv010, purv011, purv013). Markers were labeled for fragment analysis using the multitailed primer tagging method of Real et al. (2009). Fragment analysis was conducted on an ABI 3130 sequencer (Applied Biosystems) and data were scored using GENEMAPPER (version 4.0; Applied Biosystems).

\section{Genetic data analyses}

Genetic diversity of subpopulations was explored by estimating observed $\left(H_{O}\right)$ and expected $\left(H_{E}\right)$ heterozygosity using ARLEQUIN (version 3.5.1.2; Excoffier and Lischer 2010). Tests for deviation from Hardy-Weinberg Equilibrium (HWE) for each locus-population combination were carried out using exact tests implemented in ARLEQUIN. Genetic structure was quantified by estimating pairwise and global $F_{\mathrm{ST}}$ values in ARLEQUIN. These values were tested for significant deviation from panmictic expectations by 10,000 permutations of individuals among populations. Because of high levels of within-population diversity, a 
standardized value for $F_{\mathrm{ST}}$ was obtained by expressing $F_{\mathrm{ST}}$ as a proportion of the maximum value $\left(F_{\mathrm{STmax}}\right)$ that could be obtained (i.e., $F_{\mathrm{ST}}^{\prime}=F_{\mathrm{ST}} / F_{\mathrm{STmax}}$; Meirmans and Hedrick 2011). The required estimate of $F_{\mathrm{STmax}}$ was made indirectly by recoding the data file using RecodeData, (Meirmans 2006) followed by processing in ARLEQUIN. IBD was tested by correlating genetic distance (Slatkin's Linearized $\left.F_{\mathrm{ST}}\right)$ and geographic distance (coastline distance between rivers in $\mathrm{km}$ ) for each pairwise test. The correlation was tested for significance with a Mantel test in ARLEQUIN using 1000 permutations. The critical value $(\alpha)$ was corrected for multiple tests using the BY False Discovery Rate method (BY-FDR) which controls experiment-wide Type I error without the loss of power associated with the Bonferroni adjustment (Benjamini and Yekutieli 2001, Narum 2006).

For each species, the existence of distinct genetic groups in the set of individual multilocus genotypes was tested using a model-based Bayesian clustering method. The probability of an admixture model was tested for up to 8 clusters $(K)$ using STRUCTURE (version 2.3.1; Pritchard et al. 2000). Models were tested using 8 independent Markov Chain Monte Carlo (MCMC) simulations, each consisting of $1 \times 10^{6}$ iterations after a burn-in of $5 \times 10^{5}$ iterations. The most likely number of homogeneous clusters was assessed with the $2^{\text {nd }}$-order rate of change L" $(K)$ following Evanno et al. (2005) using the online application STRUCTURE HARVESTER (Earl and Vonholdt 2012). Genealogical relationships of sampled mtDNA haplotypes were estimated using statistical parsimony in TCS (version 1.21; Clement et al. 2000).

\section{RESULTS}

\section{Otolith Sr isotopes, L. sealii}

Otolith transect measurements of ${ }^{87} \mathrm{Sr} /{ }^{86} \mathrm{Sr}$ were obtained from 41 L. sealii individuals sampled from 5 rivers in Tasmania. All individual life-history profiles displayed low variability from the juvenile phase at the otolith core to the adult stage at the otolith edge and did not show evidence of a transition between isotopically distinct phases that would indicate habitat switching between marine and freshwater habitats (Fig. 2A). Individual profiles overlapped the marine standard ${ }^{87} \mathrm{Sr} /{ }^{86} \mathrm{Sr}$ value of 0.70916 with only 4 exceptions. These exceptions from the Huon River all had $\mathrm{Sr}$ isotope ratios marginally, but consistently, above the marine value (see Fig. 2A individual profile b). However, the mean (SD) ratio of $0.70981(0.00021)$ for these 4 individuals was distinctly lower than the Huon river freshwater ratio of 0.71397 (Fig. 2A), suggesting that these fish did not at any stage inhabit full freshwater. A clear pattern evident from the summary of individual profiles presented in Fig. 2A is that most otolith $\mathrm{Sr}$ isotope ratios did not overlap with the corresponding river-water value at any point in the profile. Three individuals from the Derwent River had maximum values that encompassed their river-water value (Fig. 2A), but in each case, the maximum value was a shortlived signal spike rather than a representative trend in the ${ }^{87} \mathrm{Sr} /{ }^{86} \mathrm{Sr}$ transect (see Fig. $2 \mathrm{~A}$ individual profile a, representative example of signal spike).

\section{Genetic structure, $L$. sealii}

Null alleles, large allele drop-out, stuttering artefacts, and linkage disequilibrium were not detected in the L. sealii microsatellite data set (Schmidt et al. 2013). Three significant deviations from HWE were observed from a total of 30 locus-population combinations (Table S3). Microsatellite genetic diversity was high. A total of 126 alleles were identified from 6 loci genotyped in 113 individuals with expected heterozygosity averaged across all loci and populations of $\sim 0.74$ (Table 1 ). Comparison of microsatellite diversity among populations based on allelic richness standardized to a sample size of 14 showed that the 4. Tasmanian populations shared relatively high diversity compared to the Tarwin site on the mainland (Table 1). The edited alignment of 83 L. sealii ATP sequences was 573 base pairs (bp) in length with 37 variable positions and 32 haplotypes (Fig. 1A). Haplotype diversity was moderate to high in all populations and ranged from $\sim 0.60$ to $\sim 0.85$ (Table 1). The sampled haplotypes formed a shallow network spanning a maximum of 7 steps (Fig. 1A). Two haplotypes (1 and 18, Fig. 1A) composed $52 \%$ of the total sample, whereas the remaining 30 haplotypes occurred at low frequencies of $<5 \%$ (Table $\mathrm{S} 1$ ).

The global $F_{\mathrm{ST}}$ estimate for microsatellite data was relatively low but significantly higher than the random expectation $\left(F_{\mathrm{ST}}=0.036, p<0.0001\right)$ and standardization for within-population genetic diversity produced a value $\sim 4 \times$ higher $\left(F_{\mathrm{ST}}^{\prime}=0.141\right)$. Locus-by-locus estimates are provided in Table S4. For mtDNA data, the global $F_{\mathrm{ST}}$ estimate was moderately high and significant $\left(F_{\mathrm{ST}}=0.242, p<\right.$ $0.0001)$ and the corresponding standardized measure was $\sim 2 \times$ as high $\left(\Phi_{\mathrm{ST}}=0.514, p<0.0001\right)$. Microsatellite and mtDNA data produced concordant estimates of pairwise differentiation that reflected the geographic position of sampling sites. The mainland site on the Tarwin River was significantly differentiated from all other sites for both marker types, and no mtDNA haplotypes were shared with other populations (Tables S1, S5). Samples from Tasmania's northern (Leven and Rubicon) and southern coasts (Huon and Derwent) were significantly differentiated from one another and only a single low-frequency haplotype was shared between north and south (haplotype 10, Fig. 1A; Tables S1, S5). No differentiation was found within the northern or southern groups for microsatellites or mtDNA (Table S5). Therefore, the pattern of genetic structure among the 5 river samples of $L$. sealii follows the pattern expected from the species' distribution, with 3 well differentiated groups: northern Tasmania, southern Tasmania, and 


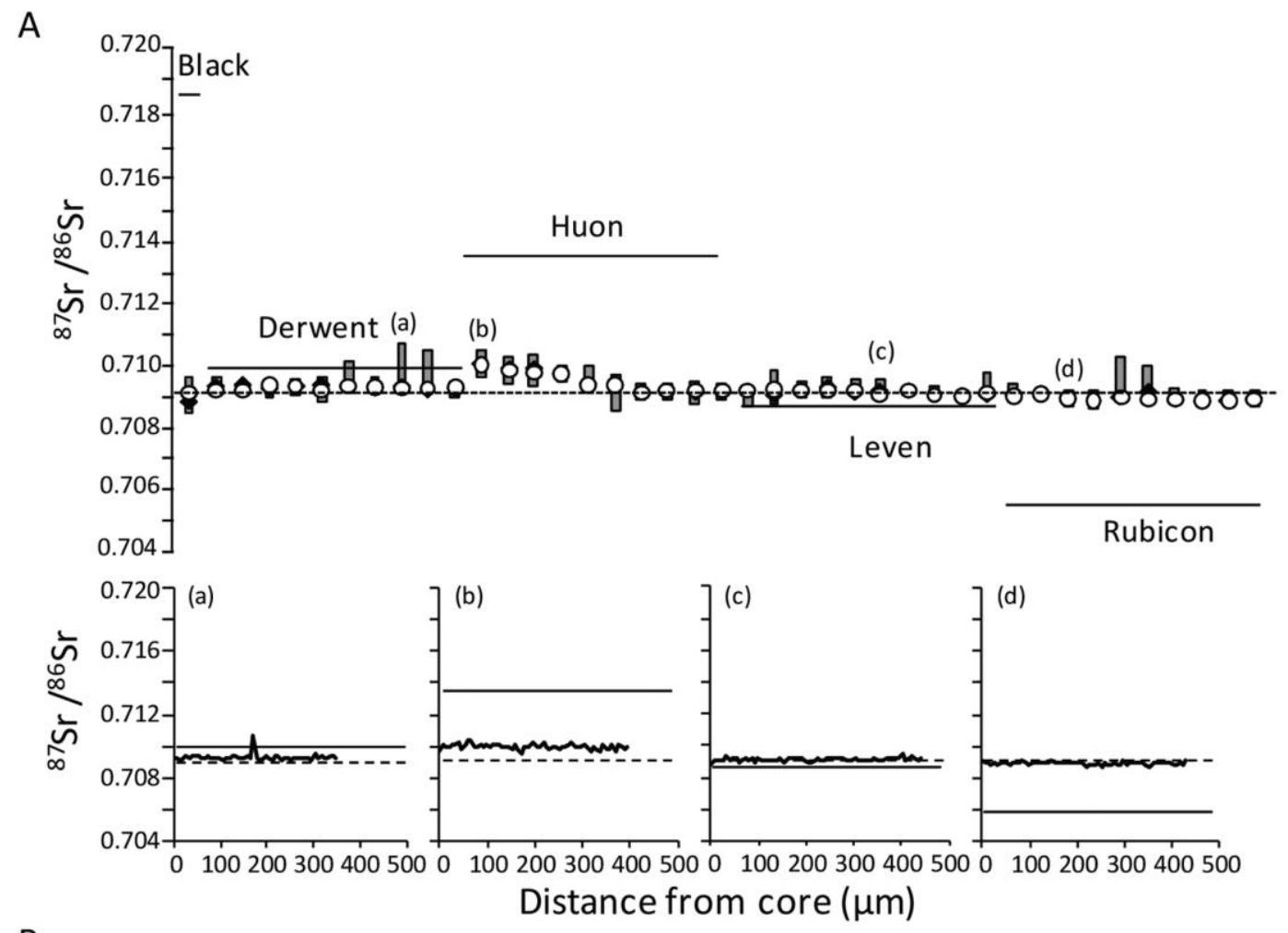

B
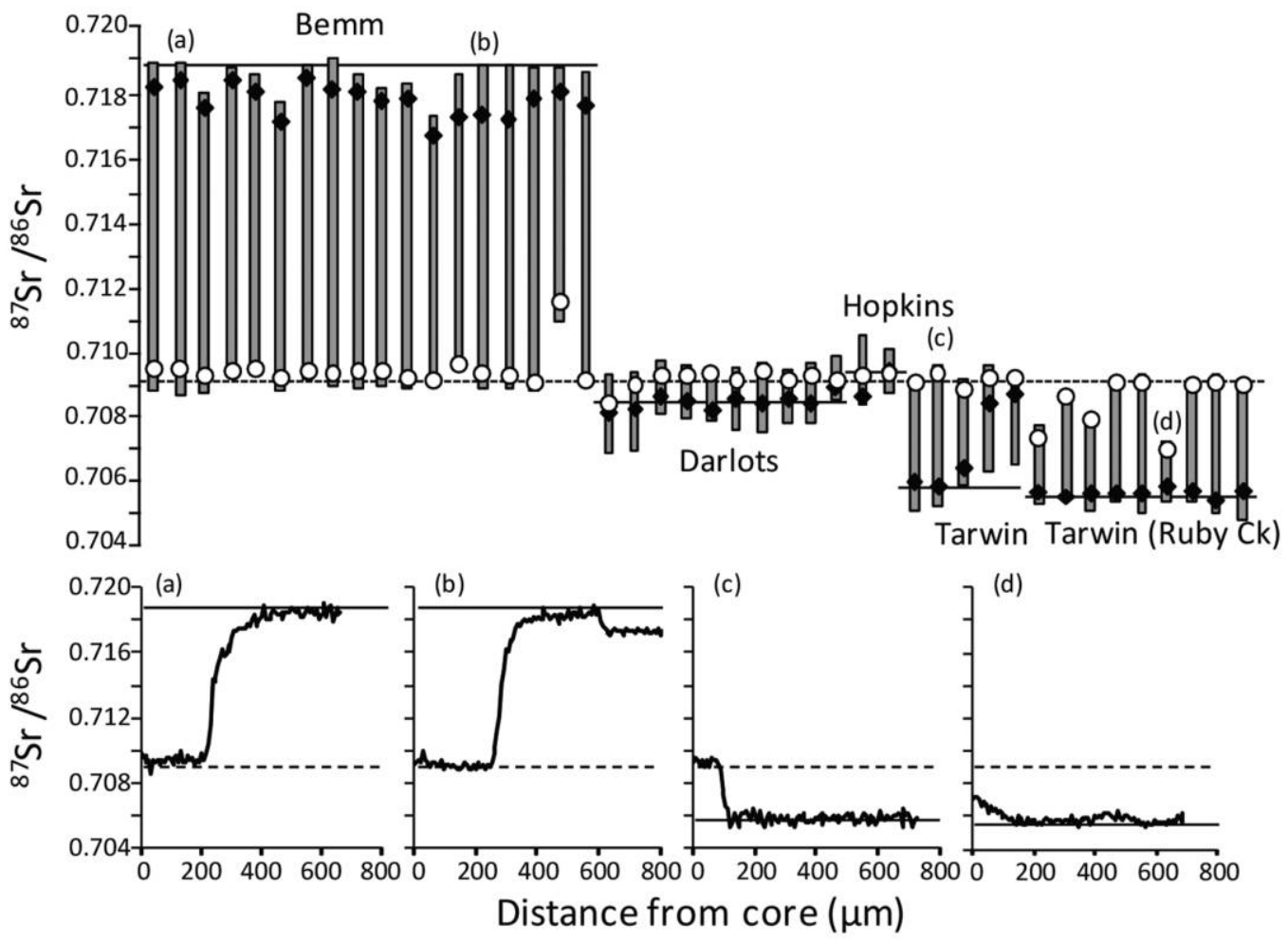

Figure 2. Summary of individual life-history profiles based on otolith Sr isotope transects in Lovettia sealii (A) and Pseudaphritis urvillii (B). Bar plots summarize otolith data obtained for each individual grouped according to river sample. Grey bars represent the ${ }^{87} \mathrm{Sr} /{ }^{86} \mathrm{Sr}$ range (maximum-minimum) over the full transect. Open circles represent the average ${ }^{87} \mathrm{Sr} /{ }^{86} \mathrm{Sr}$ value at the otolith core, taken from the first 5 point measurements spanning $\sim 26 \mu \mathrm{m}$ from the otolith primordium. Closed diamonds represent the average ${ }^{87} \mathrm{Sr} /{ }^{86} \mathrm{Sr}$ value at the otolith edge, taken from the last 5 point measurements spanning $\sim 26 \mu \mathrm{m}$ from the otolith outer edge. Dashed line denotes the seawater ${ }^{87} \mathrm{Sr} /{ }^{86} \mathrm{Sr}$ ratio $(0.70916)$. Solid lines denote the river water ${ }^{87} \mathrm{Sr} /{ }^{86} \mathrm{Sr}$ ratio for each sampling location. Four representative profiles are provided for each species. Sample codes for these fish are: Lovettia sealii 5007 (a), 4000 (b), 1005 (c), 3002 (d), and Pseudaphritis urvillii 5034 (a), 5134 (b), 7037 (c), 7139 (d). 
Victoria. Arranging the 5 populations into northern, southern, and mainland groupings for a conventional analysis of molecular variance (AMOVA) produced the following fixation indices for mtDNA: $F_{\mathrm{CT}}=0.31(p=0.06), F_{\mathrm{SC}}=0.00$ $(p=0.37), F_{\mathrm{ST}}=0.31(p<0.0001), \Phi_{\mathrm{CT}}=0.61(p<$ $0.0001), \Phi_{\mathrm{SC}}=-0.02(p=0.92), \Phi_{\mathrm{ST}}=0.60(p<0.0001)$; and for microsatellites: $F_{\mathrm{CT}}=0.05(p=0.06), F_{\mathrm{SC}}=0.00(p$ $=0.85), F_{\mathrm{ST}}=0.05(p<0.0001)$. Bayesian clustering of individual microsatellite genotypes returned the highest mean likelihood score for $K=1$ group. The $\Delta K$ method for assessing the uppermost hierarchical level of structure in the data set cannot be used to evaluate $K=1$. However, the data did not influence the posterior distribution of assignment scores for $K>1$, so no population structure is detectable in the microsatellite data set with this clustering approach.

\section{Otolith Sr isotopes, $P$. urvillii}

Otolith transect measurements of ${ }^{87} \mathrm{Sr} /{ }^{86} \mathrm{Sr}$ were obtained from 44 P. urvillii females sampled from 4 rivers: Bemm, Hopkins, Fitzroy (Darlots Creek), and Tarwin. The Tarwin sample included individuals from the main channel and from a tributary (Ruby Creek), which differed slightly in river-water $\mathrm{Sr}$ isotope ratio (Table 1; Fig. 2B). Most individual life-history profiles showed a clear modulation in $\mathrm{Sr}$ isotope ratio, starting from the otolith core at values close to the marine value, then shifting at some intermediate point in the profile to values close to the river-water $\mathrm{Sr}$ isotope ratio (see Fig. 2B individual profiles a, b, c, d). This pattern is consistent with most individuals spending a significant period of their early life in marine water before migrating into freshwater. No evidence was found for multiple movements between marine and freshwater environments, suggesting that the downstream migration to the sea described by Crook et al. (2010) using acoustic telemetry occurs only once during life.

Some exceptions to the clear migratory pattern observed in most profiles included samples from Darlots Creek and Hopkins River, where the river-water Sr isotope ratios $(0.708369,0.709272)$ were very close to the marine ratio (0.70916). This similarity made any transition between the freshwater and marine ${ }^{87} \mathrm{Sr} /{ }^{86} \mathrm{Sr}$ values along the profile difficult to discern (Fig. 2B). The profiles of 4 individuals from the Tarwin sample and 1 individual from the Bemm sample did not overlap with the marine Sr ratio at any point in the transect (Fig. 2B). This result may indicate that some individuals spend their early life histories in brackish rather than marine habitats. It also is possible that the marine phase was very short-lived in these fish and that our ${ }^{87} \mathrm{Sr} /{ }^{86} \mathrm{Sr}$ transect analyses failed to detect the marine phase.

\section{Genetic structure, $P$. urvillii}

Null alleles, large allele drop-out, stuttering artefacts, and linkage disequilibrium were not detected in the
P. urvillii microsatellite data set (Schmidt et al. 2013). Two significant deviations from HWE were observed from a total of 49 locus-population combinations (Table S6). Microsatellite genetic diversity was very high. A total of 150 alleles were identified from 7 loci genotyped in 181 individuals with expected heterozygosity averaged across all loci and populations of $\sim 0.85$ (Table 1). All of the 7 populations were similar in terms of microsatellite diversity based on allelic richness standardized to a sample size of 12 (Table 1). The edited alignment of 135 P. urvillii cyt $b$ sequences was $601 \mathrm{bp}$ in length with 23 variable positions and 21 haplotypes (Fig. 1B). Haplotype diversity was moderate to high in all populations and ranged from $\sim 0.71$ to $\sim 0.82$ (Table 1). The sampled haplotypes formed a shallow network spanning a maximum of 8 steps, similar in structure to the L. sealii network (Fig. 1B). As in L. sealii, 2 haplotypes occurred at relatively high frequency (33\%: haplotype 3, 36\%: haplotype 4; Fig. 2B, Table S2), with the remaining 19 haplotypes at relatively low frequencies.

The global $F_{\mathrm{ST}}$ estimate for microsatellite data was relatively low but significantly higher than the random expectation $\left(F_{\mathrm{ST}}=0.0094, p<0.0001\right)$, and standardization for within-population genetic diversity produced a value $\sim 7 \times$ higher $\left(F_{\mathrm{ST}}^{\prime}=0.067\right)$. Locus-by-locus estimates are provided in Table S4). For mtDNA data, the global $F_{\mathrm{ST}}$ estimate was low and nonsignificant $\left(F_{\mathrm{ST}}=0.020, p=0.099\right)$, and the corresponding standardized measure was nearly $3 \times$ higher and significant $\left(\Phi_{\mathrm{ST}}=0.058, p=0.0197\right)$. Pairwise estimates of differentiation were not concordant between microsatellite and mtDNA data sets. Five pairwise comparisons were significant (out of 21 tests) for microsatellites and one was significant for mtDNA (Table S7). A significant correlation between geographic distance and genetic distance was found among the 7 sampling sites for microsatellite data but not for mtDNA data $\left(R_{\text {msat }}^{2}=0.26\right.$, $p=0.017 ; R_{\text {mtDNA }}^{2}=0.0009, p=0.38$; Fig. S1). Bayesian clustering of individual microsatellite genotypes returned the highest mean likelihood score for $K=1$ group, and therefore, no population structure was detectable in the microsatellite data set with this clustering approach.

\section{DISCUSSION}

\section{L. sealii}

Classification of $L$. sealii as an anadromous fish has been widely accepted, and $L$. sealii is one of the few proposed representatives of this form of diadromy in the southern hemisphere (McDowall 1988, Allen et al. 2002, Gillanders 2005, Miles 2007, Helfman et al. 2009). However, the $\mathrm{Sr}$ isotope profiles presented here are not consistent with habitat switching between marine and freshwater, but instead suggest that most individuals complete their life cycle in an environment that is equal or very similar in $\mathrm{Sr}$ isotope composition to marine water (i.e., saline or brackish water). Thus, if our results are general- 
ized to the species, they suggest $L$. sealii is neither anadromous nor diadromous in the strict sense because residence in pure freshwater does not appear to occur during the life cycle. This life-history trait is unique among the Galaxiidae where all other diadromous members complete an obligatory period of residence in freshwater. Extensive sampling of $L$. sealii during the peak of the Tasmanian whitebait fishery in the 1940s demonstrated that adults commonly spawned in upper estuarine habitats (Blackburn 1950$)$ at a salinity of $0.5 \%$ o $(=0.1 \%$ chlorinity of Blackburn 1950) and above. Some spent fish may subsequently move into pure freshwater, but because most individuals live only $1 \mathrm{y}$, this short postreproductive freshwater period would not contribute to completion of the life cycle. The otolith chemistry data do not offer good resolution on whether the prespawning phase of the life cycle occurs in fully marine habitat or in estuaries because ${ }^{87} \mathrm{Sr} /{ }^{86} \mathrm{Sr}$ ratios asymptotically approach marine values very quickly across a salinity gradient, so that mid-salinity estuarine habitats are difficult to distinguish from fully marine ones (Walther and Limburg 2012). Some evidence indicates that the habitat residence of the prespawning phase of the $L$. sealii life cycle is variable, ranging from fully marine, with anecdotal accounts of schools of whitebait observed several miles out to sea $\sim 1$ mo before they begin to migrate into estuaries (Blackburn 1950), to midestuarine, with juveniles recorded in mid-austral autumn from within a coastal inlet on mainland Australia (TR, personal observation). In functional terms, $L$. sealii might best be regarded as semianadromous or even as estuarinedependent rather than truly anadromous (Elliott et al. 2007).

Genetic diversity of the $L$. sealii sample was not as high as that of the P. urvillii sample but was in the range typical of marine rather than freshwater fishes (McCusker and Bentzen 2010). Unlike P. urvillii, genetic variation was strongly structured among subpopulations, with 3 well differentiated stocks consisting of northern Tasmania, southern Tasmania, and mainland Victoria. These results agree with Blackburn's (1950) proposal that Australian whitebait were divided into northern and southern populations based on body size and pigmentation, and they support the similar conclusions reached by Pavuk (1994) based on analysis of allozymes. Blackburn (1950) also inferred that northern Tasmanian populations were homogenous because fishery-induced declines in abundance occurred simultaneously across the whole region despite differences in fishing pressure. Our results agree with this inference because our 2 northern population samples (Leven and Rubicon) were genetically homogeneous.

Genetic differentiation between southeastern Australian and Tasmanian populations of freshwater or diadromous fishes has been observed in some species (e.g.,
Retropinna spp.; JMH, unpublished data) but not others (e.g., Macquaria colonorum, Shaddick et al. 2011). Some taxa show patterns inferred to represent drainage connections along the continental shelf that joined the 2 land masses during periods of Pleistocene lowered sea level (e.g., Nannoperca australis; Unmack et al. 2011), whereas others do not follow these predictions (e.g., Galaxiella pusilla; Unmack et al. 2012). Our finding of moderate genetic divergence between Tasmania and the mainland adds to this complex biogeographic picture. It remains to be determined whether the isolated mainland population of Lovettia is a relic of a former Pleistocene distribution connected via Lake Bass or was more recently founded by dispersal from Tasmania.

Regional patterns of genetic structure evident from pairwise $F_{\mathrm{ST}}$ analyses of mtDNA and microsatellites were not supported by clustering analyses and hierarchical partitioning of variation. The Bayesian clustering method STRUCTURE was unable to recover any substructure within the microsatellite data set. This result is probably a consequence of very high microsatellite diversity that limited the amount of differentiation that could be expressed between subsets of individuals. Latch et al. (2006) showed that the minimum $F_{\mathrm{ST}}$ at which STRUCTURE could correctly recover a priori groups was 0.03 , and this value standardized for genetic diversity was $F_{\mathrm{ST}}^{\prime}=0.28$. After standardizing for genetic diversity, the overall level of differentiation for the L. sealii data set $\left(F_{\mathrm{ST}}^{\prime}=0.14\right)$ was well below the detectable limit of STRUCTURE. The performance of STRUCTURE under conditions of high genetic variation and variable sample size has already been questioned and warrants further investigation (Latch et al. 2006, Kalinowski 2011). Hierarchical partitioning of genetic variation using AMOVA also produced a nonsignificant result when populations were arranged into northern, southern, and mainland groups. However, the explanation for this result is more straightforward. It is impossible to arrange 5 populations into a hierarchical structure and obtain a significant AMOVA result using permutation testing (Fitzpatrick 2009). Sampling more rivers is the solution to this issue, but even based on our limited sampling of 5 rivers, our results are consistent with previous research suggesting that $L$. sealii is subdivided into $\geq 2$ stocks around the coast of Tasmania (Blackburn 1950, Pavuk 1994) in addition to our new finding that the recently discovered isolated population on mainland Australia may represent an independent genetic subpopulation within this species.

\section{P. urvillii}

Otolith ${ }^{87} \mathrm{Sr} /{ }^{86} \mathrm{Sr}$ profiles confirm that $P$. urvillii females switch from marine to freshwater habitat during their early life history. This transition was most clear when divergence in $\mathrm{Sr}$ isotope ratio between freshwater and ma- 
rine habitats was high relative to within-habitat variation. The ${ }^{87} \mathrm{Sr} /{ }^{86} \mathrm{Sr}$ ratio is essentially fixed throughout the ocean but varies widely among rivers depending on underlying geology (Milton and Chenery 2003, Walther and Limburg 2012). Therefore, the power of the Sr-isotope approach depends on whether the ${ }^{87} \mathrm{Sr} /{ }^{86} \mathrm{Sr}$ ratio of the chosen freshwater habitat is sufficiently different from the marine value to permit their discrimination. This was the case for the Bemm and Tarwin samples, but was less clear for Darlots (Fitzroy) and Hopkins.

No evidence indicated that any individual repeated the switch from marine to freshwater habitat more than once during its life cycle. Acoustic telemetry data for adult females were consistent with this finding and showed that the spawning migration involves rapid movement through the estuary and into the ocean with no evidence of postspawning movement back into freshwater (Crook et al. 2010). Therefore, multiple lines of evidence suggest that P. urvillii may be semelparous, although further research is required to investigate thoroughly whether females reproduce only once. Other aspects of the life cycle remain poorly understood. For example, our sampling was restricted primarily to freshwater habitats, so any marine residence within the female population would go undetected, as would the male population, which appears to be nondiadromous and to reside in estuaries or marine inlets (Hortle 1979).

Genetic diversity of the P. urvillii sample was very high. Expected heterozygosity of microsatellites and haplotype diversity of mtDNA were both similar to average values for marine fish species (McCusker and Bentzen 2010). Genetic variation was only weakly structured among subpopulations, indicating that the sampled rivers were connected by some degree of dispersal and gene flow. The observation that some pairwise comparisons were significant for microsatellites but not for mtDNA is unlikely to be biologically significant. This difference probably is a consequence of the larger number of alleles and greater sample size of microsatellite data relative to mtDNA data, which leads to higher power to detect low levels of differentiation in microsatellite data (Larsson et al. 2009). An IBD relationship was detected in the microsatellite data, so this genetic connectivity probably is mediated by a stepping-stone pattern of dispersal along the coastline. Such a pattern could arise if the dispersal kernel of juveniles is centered mostly on rivers close to the parents' point of origin, with a lower probability of long-distance dispersal. Alternatively, the IBD pattern may be mediated by limited dispersal of adults along the coastline. Similar IBD relationships have been reported for other coastline-restricted catadromous fishes (Keenan 1994, Jerry and Baverstock 1998, Shaddick et al. 2011). Therefore, it seems likely that the apparent absence of genetic structure (panmixia) observed in anguillid eels (Als et al. 2011) is an exception to the more-common pat- tern of weakly structured genetic connectivity (IBD) in other catadromous fishes. Generalizations about patterns of connectivity in diadromous organisms require further refinement to account for differences observed among the various modes of diadromy (Hughes et al. 2013).

An IBD pattern also could be produced by secondary intergradation of 2 differentiated genetic stocks (Turgeon and Bernatchez 2001) or from a hierarchical pattern of genetic structure (Meirmans 2012). Neither of these explanations seems likely for $P$. urvillii because clustering analyses did not detect hierarchical structure and no evidence was found of phylogeographic breaks in the mtDNA data that are commonly seen in obligate freshwater taxa subdivided into independent stocks along a coastline (Cook et al. 2014, Huey et al. 2014). Our study showed no evidence for multiple stocks across the sampled portion of the distribution of $P$. urvillii, but the potential for the existence of additional stocks around the coast of Tasmania, which was represented here by a single sample, cannot be ruled out. The northern part of the species' distribution in New South Wales and the western extent past Spencer Gulf in South Australia also were not sampled as part of our study.

In summary, our results provide new information and independent confirmation of previous research on the characteristics of diadromy by $P$. urvillii and information that contradicts previous suggestions that L. sealii is anadromous. Our findings also suggest that genetic structuring of $P$. urvillii conforms to an IBD model, whereas L. sealii are structured across broad geographic regions. This fundamental information on ecology and population structure is critical as a basis for formulating effective management and conservation strategies for the species. In particular, our results highlight the importance of maintaining access to upper estuarine reaches for completion of the life cycle and for maintenance of population connectivity in both species.

\section{ACKNOWLEDGEMENTS}

Funding for our study was provided by an Australian Research Council Linkage grant LP0883429 to JMH and DAC with the support of the Victorian Department of Sustainability and Environment, Queensland Department of Natural Resources and Water, Melbourne Water, and the Tasmanian Inland Fisheries Service. Assistance with genetic laboratory work was provided by Kathryn Real and Kirsty Botha. Assistance with field work was provided by Chris Belcher, Andrew Kaus, Andrew (Panda) Pickworth, John Mackenzie, Ian Magraith, Arron Strawbridge, and Neil Wellman. Rhys Coleman (Melbourne Water) and Jonathan Marshall (Queensland Department of Science, Information Technology, Innovation and the Arts) provided technical input and advice on project design. Jon Woodhead (Melbourne University) provided technical input and assistance with the otolith chemistry analyses, and Roland Maas (Melbourne University) analyzed the water samples. 


\section{LITERATURE CITED}

Allen, G. R., S. H. Midgley, and M. Allen. 2002. Field guide to the freshwater fishes of Australia. Western Australian Museum, Perth, Australia.

Als, T. D., M. M. Hansen, G. E. Maes, M. Castonguay, L. Riemann, K. Aarestrup, P. Munk, H. Sparholt, R. Hanel, and L. Bernatchez. 2011. All roads lead to home: panmixia of European eel in the Sargasso Sea. Molecular Ecology 20:1333-1346.

Benjamini, Y., and D. Yekutieli. 2001. The control of the false discovery rate in multiple testing under dependency. Annals of Statistics 29:1165-1188.

Blackburn, M. 1950. The Tasmanian whitebait, Lovettia seali (Johnston), and the whitebait fishery. Australian Journal of Marine and Freshwater Research 1:155-198.

Bradbury, I. R., and P. Bentzen. 2007. Non-linear genetic isolation by distance: implications for dispersal estimation in anadromous and marine fish populations. Marine Ecology Progress Series 340:245-257.

Chapman, B. B., C. Skov, K. Hulthen, J. Brodersen, P. A. Nilsson, L. A. Hansson, and C. Bronmark. 2012. Partial migration in fishes: definitions, methodologies and taxonomic distribution. Journal of Fish Biology 81:479-499.

Clement, M., D. Posada, and K. A. Crandall. 2000. TCS: a computer program to estimate gene genealogies. Molecular Ecology 9:1657-1659.

Cook, B. D., T. J. Page, and J. M. Hughes. 2012. Phylogeography of related diadromous species in continental and island settings, and a comparison of their potential and realized dispersal patterns. Journal of Biogeography 39:421-430.

Cook, B. D., P. J. Unmack, J. A. Huey, and J. M. Hughes. 2014. Origin of relict populations of freshwater fishes in northern Australia with common disjunct distributions (Pseudomugil gertrudae, Denariusa australis and Melanotaenia maccullochi). Freshwater Science 33:263-272.

Crandall, E. D., J. R. Taffel, and P. H. Barber. 2010. High gene flow due to pelagic larval dispersal among South Pacific archipelagos in two amphidromous gastropods (Neritomorpha: Neritidae). Heredity 104:563-572.

Crook, D. A., W. M. Koster, J. I. Macdonald, S. J. Nicol, C. A. Belcher, D. R. Dawson, D. J. O'Mahony, D. Lovett, A. Walker, and L. Bannam. 2010. Catadromous migrations by female tupong (Pseudaphritis urvillii) in coastal streams in Victoria, Australia. Marine and Freshwater Research 61:474-483.

Crook, D. A., J. I. Macdonald, and T. A. Raadik. 2008. Evidence of diadromous movements in a coastal population of southern smelts (Retropinninae: Retropinna) from Victoria, Australia. Marine and Freshwater Research 59:638-646.

Dionne, M., F. Caron, J. J. Dodson, and L. Bernatchez. 2008. Landscape genetics and hierarchical genetic structure in Atlantic salmon: the interaction of gene flow and local adaptation. Molecular Ecology 17:2382-2396.

Earl, D. A., and B. M. Vonholdt. 2012. STRUCTURE HARVESTER: a website and program for visualizing STRUCTURE output and implementing the Evanno method. Conservation Genetics Resources 4:359-361.

Elliott, M., A. K. Whitfield, I. C. Potter, S. J. M. Blaber, D. P. Cyrus, F. G. Nordlie, and T. D. Harrison. 2007. The guild approach to categorizing estuarine fish assemblages: a global review. Fish and Fisheries 8:241-268.
Evanno, G., S. Regnaut, and J. Goudet. 2005. Detecting the number of clusters of individuals using the software STRUCTURE: a simulation study. Molecular Ecology 14: 2611-2620.

Excoffier, L., and H. E. L. Lischer. 2010. Arlequin suite, version 3.5: a new series of programs to perform population genetics analyses under Linux and Windows. Molecular Ecology Resources 10:564-567.

Feutry, P., A. Vergnes, D. Broderick, J. Lambourdière, P. Keith, and J. R. Ovenden. 2013. Stretched to the limit. Can a short pelagic larval duration connect adult populations of an IndoPacific diadromous fish (Kuhlia rupestris)? Molecular Ecology 22:1518-1530

Fitzpatrick, B. M. 2009. Power and sample size for nested analysis of molecular variance. Molecular Ecology 18:3961-3966.

Fulton, W. 2000. Tasmanian whitebait-a multi-species fishery targeting migrating fishes. Pages $256-260$ in D. A. Hancock, D. C. Smith, and J. D. Koehn (editors). Fish Movement and Migration: Australian Society for Fish Biology Workshop Proceedings, Bendigo, 28-29 September 1999. Australian Society for Fish Biology, Sydney, Australia.

Fulton, W., and N. Pavuk. 1988. The Tasmanian whitebait fishery: summary of present knowledge and outline of future management plans. Inland Fisheries Commission Occasional Report 88-01. Inland Fisheries Commission, Tasmania, Australia.

Gillanders, B. M. 2005. Otolith chemistry to determine movements of diadromous and freshwater fish. Aquatic Living Resources 18:291-300.

$\rightarrow$ Griffiths, A. M., G. Machado-Schiaffino, E. Dillane, J. Coughlan, J. L. Horreo, A. E. Bowkett, P. Minting, S. Toms, W. Roche, P. Gargan, P. McGinnity, T. Cross, D. Bright, E. GarciaVazquez, and J. R. Stevens. 2010. Genetic stock identification of Atlantic salmon (Salmo salar) populations in the southern part of the European range. BMC Genetics 11:31.

Hammer, M., S. Wedderburn, and J. van Weenen. 2009. Congolli (Pseudaphritis urvillii). Pages 102-104 in Action plan for South Australian freshwater fishes. Department of Environment and Heritage, Government of South Australia (editors). Native Fish Australia (SA) Inc., Adelaide, Australia.

Helfman, G. S., B. B. Collette, D. E. Facey, and B. W. Bowen. 2009. The diversity of fishes: biology, evolution, and ecology. Wiley-Blackwell, Oxford, UK.

Hortle, M. E. 1979. The ecology of the Sandy, Pseudaphritis urvillii, in southeast Tasmania. Honours Thesis, University of Tasmania, Hobart, Australia.

Huey, J. A., B. D. Cook, P. J. Unmack, and J. M. Hughes. 2014. Broadscale phylogeographic structure of five freshwater fishes across the Australian Monsoonal Tropics. Freshwater Science 33:273-287.

Hughes, J. M., J. A. Huey, and D. J. Schmidt. 2013. Is realised connectivity among populations of aquatic fauna predictable from potential connectivity? Freshwater Biology 58: 951-966.

Jerry, D. R., and P. R. Baverstock. 1998. Consequences of a catadromous life-strategy for levels of mitochondrial DNA differentiation among populations of the Australian bass, Macquaria novemaculeata. Molecular Ecology 7:1003-1013.

Kalinowski, S. T. 2011. The computer program STRUCTURE does not reliably identify the main genetic clusters within 
species: simulations and implications for human population structure. Heredity 106:625-632.

Keenan, C. P. 1994. Recent evolution of population structure in Australian barramundi, Lates calcarifer (Bloch): an example of isolation by distance in one dimension. Australian Journal of Marine and Freshwater Research 45:1123-1148.

King, T. L., S. T. Kalinowski, W. B. Schill, A. P. Spidle, and B. A. Lubinski. 2001. Population structure of Atlantic salmon (Salmo salar L.): a range-wide perspective from microsatellite DNA variation. Molecular Ecology 10:807-821.

Larsson, L. C., J. Charlier, L. Laikre, and N. Ryman. 2009. Statistical power for detecting genetic divergence-organelle versus nuclear markers. Conservation Genetics 10:1255-1264.

Latch, E. K., G. Dharmarajan, J. C. Glaubitz, and O. E. Rhodes. 2006. Relative performance of Bayesian clustering software for inferring population substructure and individual assignment at low levels of population differentiation. Conservation Genetics 7:295-302.

Limburg, K. E., and J. R. Waldman. 2009. Dramatic declines in North Atlantic diadromous fishes. BioScience 59:955-965.

Lord, C., J. Lorion, A. Dettai, S. Watanabe, K. Tsukamoto, C. Cruaud, and P. Keith. 2012. From endemism to widespread distribution: phylogeography of three amphidromous Sicyopterus species (Teleostei: Gobioidei: Sicydiinae). Marine Ecology Progress Series 455:269-285.

Lowe, W. H., and F. W. Allendorf. 2010. What can genetics tell us about population connectivity? Molecular Ecology 19: 3038-3051.

Maas, R., M. B. Kamenetsky, and N. V. Sobolev. 2005. Sr, Nd, and $\mathrm{Pb}$ isotope evidence for a mantle origin of alkali chlorides and carbonates in the Udachnaya kimberlite, Siberia. Geology 35:549-552.

McArthur, J. M., and R. J. Howarth. 2004. Sr-isotope stratigraphy: the Phanerozoic ${ }^{87} \mathrm{Sr} /{ }^{86} \mathrm{Sr}$-curve and explanatory notes. Pages 96-105 in F. Gradstein, J. Ogg, and A. G. Smith (editors). A geological timescale 2004. Cambridge University Press, Cambridge, UK.

McCusker, M. R., and P. Bentzen. 2010. Positive relationships between genetic diversity and abundance in fishes. Molecular Ecology 19:4852-4862.

McDowall, R. M. 1988. Diadromy in fishes: migrations between freshwater and marine environments. Timber Press, Portland, Oregon.

McDowall, R. M. 2001. Anadromy and homing: two life-history traits with adaptive synergies in salmonid fishes? Fish and Fisheries 2:78-85.

McDowall, R. M. 2008. Diadromy, history and ecology: a question of scale. Hydrobiologia 602:5-14.

Meirmans, P. G. 2006. Using the AMOVA framework to estimate a standardized genetic differentiation measure. Evolution 60:2399-2402.

Meirmans, P. G. 2012. The trouble with isolation by distance. Molecular Ecology 21:2839-2846.

Meirmans, P. G., and P. W. Hedrick. 2011. Assessing population structure: $F_{\mathrm{ST}}$ and related measures. Molecular Ecology Resources 11:5-18.

Miles, N. G. 2007. Biology and ecology of diadromous fishes in south eastern Australia. University of Wollongong, Wollongong, Australia. $\rightarrow$ Milton, D. A., and S. R. Chenery. 2003. Movement patterns of the tropical shad hilsa (Tenualosa ilisha) inferred from transects of ${ }^{87} \mathrm{Sr} /{ }^{86} \mathrm{Sr}$ isotope ratios in their otoliths. Canadian Journal of Fisheries and Aquatic Sciences 60:1376-1385.

$\rightarrow$ Milton, D. A., and S. R. Chenery. 2005. Movement patterns of barramundi Lates calcarifer, inferred from ${ }^{87} \mathrm{Sr} /{ }^{86} \mathrm{Sr}$ and $\mathrm{Sr} /$ $\mathrm{Ca}$ ratios in otoliths, indicate non-participation in spawning. Marine Ecology Progress Series 301:279-291.

Myers, G. S. 1949. Usage of anadromous, catadromous and allied terms for migratory fishes. Copeia 2:89-97.

Narum, S. R. 2006. Beyond Bonferroni: less conservative analyses for conservation genetics. Conservation Genetics 7: $783-787$.

Near, T. J., J. J. Pesavento, and C. H. C. Cheng. 2004. Phylogenetic investigations of Antarctic notothenioid fishes (Perciformes: Notothenioidei) using complete gene sequences of the mitochondrial encoded $16 \mathrm{~S}$ rRNA. Molecular Phylogenetics and Evolution 32:881-891.

Palmer, M. R., and J. M. Edmond. 1989. The strontium isotope budget of the modern ocean. Earth and Planetary Science Letters 92:11-26.

Paton, C., J. Hellstrom, B. Paul, J. Woodhead, and J. Hergt. 2011. Iolite: freeware for the visualisation and processing of mass spectrometric data. Journal of Analytical Atomic Spectrometry 26:2508-2518.

Pavuk, N. C. 1994. Population genetics of selected whitebait species: Galaxias maculatus (Jenyns) and Lovettia sealii (Johnston). MSc Thesis, University of Tasmania, Hobart, Australia.

Pin, C., D. Briot, C. Bassin, and F. Poitrasson. 1994. Concomitant separation of strontium and sumarium neodymium for isotopic analysis in silicate samples, based on specific extraction chromatography. Analytica Chimica Acta 298:209-217.

Pritchard, J. K., M. Stephens, and P. Donnelly. 2000. Inference of population structure using multilocus genotype data. Genetics 155:945-959.

Raadik, T. A. 2008a. Family Galaxiidae: galaxiids, mudfishes, whitebaits. Pages 217-220 in M. Gomon, D. Bray, and R. Kuiter (editors). Fishes of Australia's Southern Coast. New Holland Press, Sydney, Australia.

Raadik, T. A. 2008b. Family Pseudaphritidae: temperate icefishes. Pages 669-670 in M. Gomon, D. Bray, and R. Kuiter (editors). Fishes of Australia's Southern Coast. New Holland Press, Sydney, Australia.

$\rightarrow$ Real, K. M., D. J. Schmidt, and J. M. Hughes. 2009. Mogurnda adspersa microsatellite markers: multiplexing and multitailed primer tagging. Conservation Genetics Resources 1: 411-414.

Rolls, R. J. 2011. The role of life-history and location of barriers to migration in the spatial distribution and conservation of fish assemblages in a coastal river system. Biological Conservation 144:339-349.

Sambrook, J., E. F. Fritsch, and T. Maniatis. 1989. Molecular cloning: a laboratory manual. Cold Spring Harbor Laboratory Press, Woodbury, New York.

Schmidt, D. J., D. A. Crook, J. P. O'Connor, and J. M. Hughes. 2011. Genetic analysis of threatened Australian grayling Prototroctes maraena suggests recruitment to coastal rivers from an unstructured marine larval source population. Journal of Fish Biology 78:98-111. 
Schmidt, D. J., K. M. Real, D. A. Crook, and J. M. Hughes. 2013. Microsatellite markers for Australian temperate diadromous fishes Pseudaphritis urvillii (Bovichtidae) and Lovettia sealii (Galaxiidae). Conservation Genetics Resources 5:347-349.

Shaddick, K., D. M. Gilligan, C. P. Burridge, D. R. Jerry, K. Truong, and L. B. Beheregaray. 2011. Historic divergence with contemporary connectivity in a catadromous fish, the estuary perch (Macquaria colonorum). Canadian Journal of Fisheries and Aquatic Sciences 68:304-318.

Sorensen, P. W., and K. A. Hobson. 2005. Stable isotope analysis of amphidromous Hawaiian gobies suggests their larvae spend a substantial period of time in freshwater river plumes. Environmental Biology of Fishes 74:31-42.

Spice, E. K., D. H. Goodman, S. B. Reid, and M. F. Docker. 2012. Neither philopatric nor panmictic: microsatellite and mtDNA evidence suggests lack of natal homing but limits to dispersal in Pacific lamprey. Molecular Ecology 21:2916-2930.

Thacker, C. E., P. J. Unmack, L. Matsui, and N. Rifenbark. 2007. Comparative phylogeography of five sympatric Hypseleotris species (Teleostei: Eleotridae) in south-eastern Australia reveals a complex pattern of drainage basin exchanges with little congruence across species. Journal of Biogeography 34:1518-1533.

Turgeon, J., and L. Bernatchez. 2001. Clinal variation at microsatellite loci reveals historical secondary intergradation between glacial races of Coregonus artedi (Teleostei: Coregoninae). Evolution 55:2274-2286.

$\rightarrow$ Unmack, P. J., J. C. Bagley, M. Adams, M. P. Hammer, and J. B. Johnson. 2012. Molecular phylogeny and phylogeography of the Australian freshwater fish genus Galaxiella, with an emphasis on dwarf galaxias (G. pusilla). PLoS ONE 7:e38433.

Unmack, P. J., M. P. Hammer, M. Adams, and T. E. Dowling. 2011. A phylogenetic analysis of pygmy perches (Teleostei: Percichthyidae) with an assessment of the major historical influences on aquatic biogeography in southern Australia. Systematic Biology 60:797-812.
Vaha, J. P., J. Erkinaro, E. Niemela, and C. R. Primmer. 2007. Life-history and habitat features influence the within-river genetic structure of Atlantic salmon. Molecular Ecology 16: 2638-2654.

Waldman, J., C. Grunwald, and I. Wirgin. 2008. Sea lamprey Petromyzon marinus: an exception to the rule of homing in anadromous fishes. Biology Letters 4:659-662.

Walther, B. D., and K. E. Limburg. 2012. The use of otolith chemistry to characterize diadromous migrations. Journal of Fish Biology 81:796-825.

Waples, R. S., A. E. Punt, and J. M. Cope. 2008. Integrating genetic data into management of marine resources: how can we do it better? Fish and Fisheries 9:423-449.

Waters, J. M., L. H. Dijkstra, and G. P. Wallis. 2000. Biogeography of a southern hemisphere freshwater fish: how important is marine dispersal? Molecular Ecology 9:1815-1821.

Wedderburn, S. D., M. P. Hammer, and C. M. Bice. 2012. Shifts in small-bodied fish assemblages resulting from drought-induced water level recession in terminating lakes of the Murray-Darling Basin, Australia. Hydrobiologia 691: $35-46$.

Woodhead, J., S. Swearer, J. Hergt, and R. Maas. 2005. In situ Sr-isotope analysis of carbonates by LA-MC-ICP-MS: interference corrections, high spatial resolution and an example from otolith studies. Journal of Analytical Atomic Spectrometry 20:22-27.

Woods, R. J., J. I. Macdonald, D. A. Crook, D. J. Schmidt, and J. M. Hughes. 2010. Contemporary and historical patterns of connectivity among populations of an inland river fish species inferred from genetics and otolith chemistry. Canadian Journal of Fisheries and Aquatic Sciences 67: 1098-1115.

Zampatti, B. P., C. M. Bice, and P. R. Jennings. 2010. Temporal variability in fish assemblage structure and recruitment in a freshwater-deprived estuary: The Coorong, Australia. Marine and Freshwater Research 61:1298-1312. 